\title{
Information Source Before Travelling and Choice of Traveling Mode
}

\author{
Bilal Ahmad Ali Al-khateeb, Imam Mohammad Ibn Saud Islamic University, Riyadh, Saudi Arabia \\ iD https://orcid.org/0000-0001-8708-0709 \\ Asef Mohammad Ali Al-khateeb, Imam Mohammad Ibn Saud Islamic University, Riyadh, Saudi Arabia
}

\begin{abstract}
The ability to attract tourists is crucial for the success of tourism firms in Malaysia. This has therefore raised a major concern on which information sources tourists use when making choices on their traveling mode as well as the destination. It is on this basis that tourism operators; tourism providers and managers of tourist destinations are particularly concerned with which information source or media to use to attract tourists to tourism destinations. This study investigates the relationship between information source before traveling and choice of traveling mode among Arab tourists coming to Malaysia. The study adopted a cross-sectional survey design with convenient sampling technique to generate questionnaire data from 358 participants who are mainly tourists from three major tourism attraction centers in Malaysia. The questionnaire data was analysed using multiple regression analysis technique to determine the relationship between information source and choice of traveling mode among Arab tourists coming to Malaysia. First, the overall findings show that information source before traveling among Arab tourists coming to Malaysia is significantly related to the choice of traveling mode. Further findings revealed that both tourism service providers and tourism information centers sources but not travel agent source are significantly related to the choice of traveling mode among Arab tourists coming to Malaysia. The study concludes that the choice of traveling mode among Arabs coming to Malaysia is mainly determined by tourism service providers and tourism information centers sources of information and not travel agent source of information. The outcomes of the study have significant managerial implications for tourism operators, tourism providers and managers of tourist destinations as well as tourism policy makers in Malaysia.
\end{abstract}

\section{KEYWORDS}

Malaysia, Tourism Information Centers, Tourism Service Providers, Travel Agent, Traveling Mode

\section{INTRODUCTION}

There is no doubt that studies on tourism are fast drawing attention among the academics, practitioners including governments in different countries of the world (Chetthamrongchai, 2017; Chiappa \& Balboni, 2019). In some countries across the globe, tourism has become an important sector or subsector of the economy generating significant revenue for any country (Chu and Luckanavanich, 2018). Most Asian countries such as Malaysia, Thailand, etc., are presently benefiting from the huge revenue from the tourism sector. Globally, tourism business is in its booming period. For instance, the projection by the world travel and tourism Council for the tourism industry in Southeast Asia has been deemed to be very significant and strong (Malaysian Tourism Promotion Board (MTPB), 2019).

\section{DOI: 10.4018/IJTHMDA.2020010103}

This article, originally published under IGI Global's copyright on October 18, 2019 will proceed with publication as an Open Access article starting on January 20, 2021 in the gold Open Access journal, International Journal of Tourism and Hospitality Management in the Digital Age (converted to gold Open Access January 1, 2021), and will be distributed under the terms of the Creative Commons Attribution License (http://creativecommons.org/licenses/by/4.0/) which permits unrestricted use, distribution, and production in any medium, provided the author of the original work and original publication source are properly credited. 
In Malaysia for instance, tourism industry is currently at its boom, call it "tourism boom". It is recorded that tourist's arrivals in Malaysia has continued to increase by $14.3 \%(2,078,485)$ in October 2009 compared with 1,818,304 in the same month in 2008 (New Straits Times, January 4, 2010), despite the financial crisis facing the world. From January to October in 2009, Malaysia has seen an increase of 7.2 per cent in tourists' arrival to 19.45 million compared with 18.14 million in the same period in 2008. Also, the current tourism arrivals in Malaysia in 2018 showed about 25.8 million tourists with RM84.1 billion receipts (Malaysian Tourism Promotion Board (MTPB), 2019). This is a tremendous and significant increase compared to 2009 and 2008 when only 2,078,485 and 1,818,304 were recorded respectively. This is equally restated by the Tourism, Art and Culture Minister (MoTAC), Datuk Mohamaddin Ketapi that the Malaysian tourism sector has contributed RM84.1 Billion to the national economy in 2018 compared to the previous year which recorded RM82.2 billion, about 2.2 percent increase. This shows the resilience of Malaysia's tourism industry (Malaysian Tourism Promotion Board (MTPB), Head Office, 2019).

Concerning the Arab tourists coming to Malaysia, it is observed that Malaysia has become a destination of choice for Arabs, with the country attracting a larger number of tourists from the Middle East compared to previous years. For example, the data provided by Mat, Zakaria, \& Jusoff (2009) shows that there have been yearly increase in the number of Arab tourists coming to Malaysia. For example, the data showed an increase of $23.9 \%$ in 1999; $46.5 \%$ in 2000 and $87.1 \%$ increase in 2001 while it is expected to soar higher by $90 \%$ in the near future. As expected, in 2018, nearly 33,000 Arab tourists visited Malaysia, up from 27,000 in 2017 (Arabnews, 2019). Still the number of Arab tourists coming to Malaysia is expected to rise further as Malaysia continues to position itself as a Muslimfriendly, halal haven. However, one major problem that is of concern to the Arab tourists coming to Malaysia is the sources of getting information before embarking on their tourism adventure. For instance, the tourists have just discovered that the sources of their information before traveling play a crucial role in determining their choice of traveling mode such as the use of air, water and train. This has therefore raised a major concern on which information sources tourists use when making choices on their traveling mode as well as the destination. It is on this basis that tourism operators, tourism providers and managers of tourist destinations are particularly concerned with which information source or media to use to attract tourists to tourism destinations (Korneliussen \& Greenacre, 2016).

In their study on cross-cultural information sources used by European tourists, Chu and Luckanavanich (2018), noted that although travelers happen to receive abundance of information from many sources before they actually visit the place, however, this amount of information from several sources have directly or indirectly influence the receiver's travel intention. Apart from that, this amount of information from different sources equally affects the choice of traveling mode the tourists choose. Also, Fisher, Petersen \& Burstein (2017) observed that there is lack of awareness on information sources among the tourists. They argued that tourists need reliable information sources which are however scattered but not easy to find. In this case of Arab tourists, often decisions are made based on unreliable sources which then affect their choice of travelling mode. Thus, there is a limited awareness and understanding of the background of those travelling and how information is sourced for decision making on traveling mode (Fisher, Petersen \& Burstein, 2017). Also, earlier studies such as Fodness and Murray (1997) and Grønflaten (2009b) have acknowledged that there is a problem of information sources among tourists, that is, who provides information about tourism to them? To this end, Fodness and Murray (1997) claim that the most pressing need is for more systematic research describing how and why travelers-tourists source for and use information regarding tourism especially before embarking on tourism adventures. As a result, they suggested that future research is required in order to examine travelers' use of different information choice strategies through the analysis of perceptions of the alternatives available to them for trip planning, and that such research should address the dimensions underlying information choice strategy preferences. For example, it is important to know what causes different tourists to choose specific sources to plan their trips (Fodness \& Murray, 1997). (Grønflaten, 2009a) and Fodness and Murray (1997) have identified several 
information sources such as travel agents, tourism service providers, tourism information centers etc. in which they argued that these information sources affect choice of traveling mode. However, there is lack of empirical testing on how these information sources (Al-khateeb \& Dahalin, 2013, 2015; Al-khateeb, 2019) affect the choice of traveling mode particularly within the context of Arab tourists coming to Malaysia. Therefore, this study aims to determine the influence of travel agents, tourism service providers and tourism information centers source on the choice of traveling mode of Arab tourists coming to Malaysia.

\section{LITERATURE REVIEW}

\section{Information Source Before and the Choice of Traveling Mode (Information Choice strategy)}

First and foremost, information source can be simply described as the motivated activation or acquisition of knowledge stored in memory or acquisition of information from the environment (Korneliussen \& Greenacre, 2016). In other words, it is also the search for information at the early step in the decision-making process of tourists. Fodness and Murray (1997) state that information source before is described as any information source obtained by the potential tourism travelers prior to making the tourism adventure.

Furthermore, on whether information sources affect choice of traveling mode among the tourists, Chetthamrongchai (2017) argued that information sources affect destination image. For example, the tourist will make a decision whether to travel to a particular destination after building an image based upon those sources. The travelers' choice of information is an important issue that cannot be ignored in the field of tourism as it affects tourists' plan as well as their choice of traveling mode. The study by Grønflaten (2009a); Grønflaten (2009b) and Jansen and Rieh (2010) noted that information sources used by the tourism travelers are associated with the information choice of strategy which also includes traveling mode. However, the study is limited in scope and coverage as Arab tourists were not included in the study. Chiappa \& Balboni (2019) examined the travellers' choice of information sources and information channels for domestic trips with specific focus on information search perspective. The major objective of the study was to identify which factors in terms of different sociodemographic and characteristics and travel-related variables that really affect traveller's information search from a travel agency or from a service provider (i.e. information source choice). The study adopted a survey questionnaire research design as suggested by Grønflaten (2009a) with a convenience sampling technique which was used to draw 363 domestic respondents who are mainly tourists between the age of 18 years and above in the island of Sardinia, Italy (short-haul trip). Also, the study collected data through an ad-hoc questionnaire administrated face-to-face by two trained interviewers at airport and port areas in Olbia, one of the main gateways to the region. From the analysis, the study found that travel agent is the most important information source and channels than both service provider and tourist office when making their choices and the related priority. Also, it was found that a higher length of stay is associated to the use of a face-to-face information source, rather than a digital information source. Additionally, the study equally reported that mode of travel and age were not significantly associated with either the source or the channel decision alone, these variables resulted to be significantly associated with the strategy choice. In their study of the influence of social media use and travel motivation on the perceived destination image and travel intention to Taiwan of the Thai people, Chu and Luckanavanich (2018) found that social media is an effective predictor of people's travel intention and destination image. They concluded that people frequently use social media to get traveling information seem to have better destination image and higher travel intention.

Similar to the above, Chetthamrongchai (2017) in his study investigated the influence of travel motivation, information sources and tourism crisis on tourists' destination image with a view to develop a destination image theoretical model through tourists' travel motivation, information and crisis perception. The study sampled all international travellers who visited Thailand during 
August to September 2015 in which the target population was drawn from the top five inbound tourist markets of Chiangmai, Pataya, Phuket, and Bangkok. It adopted a survey questionnaires method that was distributed among group tours or individual tours. Data analysis was done using the LIEREL programme and Structural equation modeling (SEM) and the study found that Thailand's travel motivation, travel motivation, crises, information sources in the normal situation and in an unusual occurrence significantly exert influence on Thailand's destination image, and that a positive attitude towards travel motivation represents a factor having an influential effect on Thailand's travel motivation.

In a related development, Fisher, Petersen and Burstein (2017) studied the importance of reliable information sources for prospective medical travelers. The study noted that there lack of awareness risk among those travelling for treatment abroad because of this they need reliable information sources which are however, scattered and not easy to find. The study adopted an interviews approach with a sample of 51 Australians who had travelled for stem cell treatment. The data highlight that health travelers are likely to search extensively using a wide range of sources including information on clinics' websites, Facebook, blogs, friends and family. Interviewees highlight that often decisions are made based on unreliable sources.

In a cross-cultural study, Korneliussen and Greenacre (2016) investigated information sources used by European tourists. Specifically, the study attempts to determine which information sources European tourists use when making decisions about their travel/ holiday plans. Based on this, a survey data was generated from 27 member countries of the European Union. The survey data generated was analysed and the findings revealed that there are systematic differences in how information sources are related to one another and that the various national cultures within the European Union have influence on tourists' use of information sources. Additionally, the study revealed six segments of information source behaviour that reflect economic development and the national cultures of European nations. It is also noted that tourists can segment their information sources using economic development and national culture.

Furthermore, the source of information before embarking on tourism also affects the information choice of travelers. This is due to the information at hand before such an encounter with an environment required as a place that is relevant for the tourist to make use of. It can also be attributed the Media richness theory which clearly stipulates that the richness of information source has a direct positive effect on the transmitted information which can be shared between the people as seen in (Tan \& Arnott, 1999). Going by the traveler's choice of information, there is clear evidence from the study of Grønflaten (2009b) which also reviews that information sources can never be out of place or ignored as it affects the travelers' choices of information as derived from the travel agents and service providers, as well as the internet and face-to-face as information channels.

Empirical findings by previous studies such as Grønflaten (2009a); Grønflaten (2009b)andJansen and Rieh (2010) have acknowledged that travelers choice of information is affected or determined by a number of factors such as information source and information channels. For instance, a qualitative study conducted by Grønflaten (2009a) on factors that affect traveler's choice of information revealed that information source and information channels are among the identified factors. Thus, information source is a good determinant of information choice of the travelers. This is also in line with the Media Richness theory which emphasizes on the richness of the information source to transmit or share information between people (Tan \& Arnott, 1999). Also, another study by Grønflaten (2009b) on traveler's choice of information found that information sources such as travel agents and service providers; and information channels such as face-to-face and the internet significantly affect travelers' choice of information.

Tourism information becomes necessary to be distinguished by knowing the various methods and channels; this will make the Arab tourists to also know the differences as involved. The search behavior of the Arab tourists will be made known when there is clearly an understanding between the different sources such as travel agents and primary source, face-to-face, communication, and internet 
channels Grønflaten (2009b). Therefore, within the context of this study, information source before is conceptualized as travel agents, tourism service providers and tourism information centers which are external to the tourists. Thus, the focus of this study is external information source before. They represent the sources of information for the tourist before they embark on tourism pleasure. In other words, it shows where the tourists obtained their information about tourism adventure before the actual tourism journey is embarked on. These factors are assumed to be very crucial in determining the choice of traveling mode of Arab tourists before coming actually embarking on their tourism adventures. Hence, the information sources before in the inform of travel agents, tourism service providers and tourism information centers are believed to determine the choice of traveling mode of the Arab tourists coming to Malaysia.

\section{RESEARCH METHODOLOGY}

\section{Research Design}

This study adopts a cross-sectional questionnaire survey with a quantitative approach. It is concerned with a quantitative data and then applies statistical analysis in the analysis of the data being collected (Saidu, 2006). Amin and Khan (2009) and Khurshid (2008) affirmed that quantitative questionnaire approach is suitable in conducting a research in social science research.

\section{Population and Sampling Technique}

The population of this study covers all the Arab tourists coming to Malaysia from three major tourism attraction centers in Malaysia as of the time this study was conducted. In 2018 alone, there are 33,000 Arab tourists that visited Malaysia (Arabnews, 2019). This study adopts a convenient sampling approach of non-probability sampling technique. It employed Krejcie and Morgan (1970) general scientific guideline $\left(\mathrm{S}=\mathrm{X}{ }^{2} \mathrm{NP}(1-\mathrm{P}) \mathrm{d}^{2}(\mathrm{~N}-1)+\mathrm{X}{ }^{2} \mathrm{P}(1-\mathrm{P})\right.$ for determining a sample size in order to determine the sample size of this study. The sample size for this study is 500 .

\section{Measurement of Variables}

For measurement, the information sources are travel agents, service providers, information center, journalists/ writers, other travelers, and friends/ family adapted from the work by (Grønflaten, 2005). The choice of traveling mode variable was equally measured with five (5) items reflecting various methods and channels choosing by the Arab tourists when traveling to Malaysia for tourism.

\section{Data Collection}

A questionnaire was employed to elucidate data from a large population of Arab tourists from Saudi Arabia, UAE, Bahrain, Qatar, Oman, Iraq, Kuwait, Jordan, Syria, Palestine, Lebanon, Yemen and Libya in Malaysia between 2012 - 2014 through self-administration questionnaire procedure. In all 500 copies of questionnaire were distributed and 385 copies were retrieved accounting for $77 \%$ response rate.

\section{Conceptual Framework}

Although there are several theories that could be used to underpin this study that is by a way of explaining the relationship between the variables being investigated in this study, however, this study would focus on communication theory to explain the relationship between information source and choice of travelling mode. Communication theory was proposed by S. F. Scudder in the year 1980. The theory posits that all living beings existing on the planet communicate; however, the mode of communication tends to differ considerably. For example, mothers understand that a child is hungry through the child's cry. In this case, cry has demonstrated a form of communication to express his hunger and he needs food. This is also applicable when a child is injured and then cries out for urgent 
medical attention. Therefore, the common acceptable believe of communication theory is that "all living beings whether they are plants, animals, human beings communicate through sound, speech, visible changes, body movements, gestures or in the best possible way to make the others aware of their thoughts, feelings, problems, happiness or any other information".

Amadi and Paul (2017) in their study adopted Scudder (1980) communication theory to explain how student-teacher communication influences students' academic achievement for effective teaching and learning. They posit that communication is the first source of students' academic achievement. That is, if the students failed to communicate then they will not be able to obtain the necessary information required for academic achievement. Scudder (1980) explained that communication process may be understood as a source communicating to a destination, where the source provides information to the destination which enables the destination to make choices. Thus, the choice of traveling mode of the tourists depends largely on the information and the source of such information. For example, if the information source is poor or unreliable, then the choice of traveling mode would be badly affected. This is more reason why many tourists make wrong choices of mode of traveling. Hence, there is a strong connection between information source before traveling and choice of traveling mode among the tourists (Figure 1).

H1: Information sources before traveling significantly influences Choice of traveling mode Arab tourists coming to Malaysia

\section{Descriptive Analysis Result}

The descriptive analysis was used to determine the position, the result of the descriptive analysis in table 1 indicates for. Gender, 193 (53.9\%) for male and 165 (46.1\%) for the female. For the age, the result indicates that $103(28.8 \%)$ are under 25 years, $98(27.4 \%)$ are between 25 to 35 years, 56 $(15.6 \%)$ are between 35 to 44 years, $81(22.6 \%)$ are between 45 to 54 age bracket while 20 (5.6\%) are above 55 years. For the nationality, the result also shows that 114 (31.8\%) of the respondents are from Saudi Arabia, $56(15.6 \%)$ are from UAE, $40(11.2 \%)$ are from Bahrain, $40(11.2 \%)$ are from Qatar, 38 (10.6\%) are from Oman while 24 (6.7\%), 20 (5.6\%), 8 (2.2\%), $5(1.4 \%), 3(1.1 \%), 4$ $(1.1 \%), 4(1.1 \%)$ and $2(.6 \%)$ are from Iraq, Kuwait, Jordan, Syria, Palestine, Lebanon, Yemen and Libya respectively. Similarly, for married status, 217 (60.6\%) of the respondents are married while $141(39.4 \%)$ are not married. Accordingly, the result shows that $84(23.5 \%)$ of the respondents have a high school education, $85(23.7 \%)$ are diploma holders, $128(35.8 \%)$ have degrees, $56(15.6 \%)$ of them have master's while 5 (1.4\%). Also for monthly income, the result shows that $14(43.9 \%)$ of the respondents are on a salary below RM 20,000, 50 (14.0\%) are between the income of RM 21,000 and RM 30,000, 63 (17.6\%) of them are between the income of RM 31,000 and RM 41,000, 104 (29.1\%) are also between the salary of RM 41,000 and RM 50,000, 127 (35.5\%) while majority of them earned a monthly income of a list RM 50,000. Furthermore, the result also indicates that 173 $(48.3 \%)$ of the respondents have visited Malaysia while 185 (51.7\%) have not visited Malaysia. It further shows that the majority of respondents $207(57.8 \%)$ is between 0 to 2 years, number of years traveling to Malaysia while $65(18.2 \%), 57(15.9 \%), 26(7.3 \%)$ and $3(.8 \%)$ are between 2 and 4 years, 4 and 6 years, 6 and 8 years, and above 10 years (Table 1 ).

Figure 1. Research model information source and choice of traveling mode

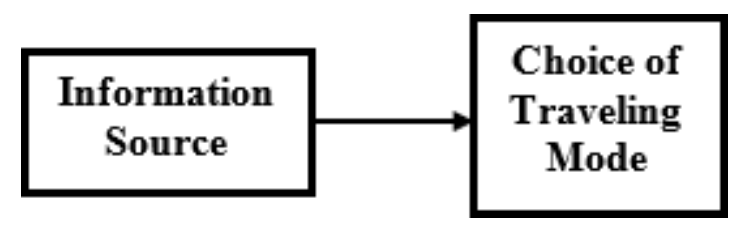


Table 1. Descriptive analysis result

\begin{tabular}{|c|c|c|}
\hline $\mathbf{N}$ & Frequency & Percentage \\
\hline \multicolumn{3}{|l|}{ Gender: } \\
\hline $\begin{array}{l}\text { Male } \\
\text { Female } \\
\text { Total }\end{array}$ & $\begin{array}{l}193 \\
165 \\
358\end{array}$ & $\begin{array}{l}53.9 \\
46.1 \\
100.0\end{array}$ \\
\hline \multicolumn{3}{|l|}{ Age: } \\
\hline $\begin{array}{l}\text { Under } 25 \\
25-34 \\
35-44 \\
45-54 \\
\text { Above } 55 \\
\text { Total }\end{array}$ & $\begin{array}{l}103 \\
98 \\
56 \\
81 \\
20 \\
358\end{array}$ & $\begin{array}{l}28.8 \\
27.4 \\
15.6 \\
22.6 \\
5.6 \\
100.0\end{array}$ \\
\hline \multicolumn{3}{|l|}{ National: } \\
\hline $\begin{array}{l}\text { Saudi Arabia } \\
\text { UAE } \\
\text { Bahrain } \\
\text { Qatar } \\
\text { Oman } \\
\text { Iraq } \\
\text { Kuwait } \\
\text { Jordan } \\
\text { Syria } \\
\text { Palestine } \\
\text { Lebanon } \\
\text { Yemen } \\
\text { Libya } \\
\text { Total }\end{array}$ & $\begin{array}{l}114 \\
56 \\
40 \\
40 \\
38 \\
24 \\
20 \\
8 \\
5 \\
3 \\
4 \\
4 \\
2 \\
358\end{array}$ & $\begin{array}{l}31.8 \\
15.6 \\
11.2 \\
11.2 \\
10.6 \\
6.7 \\
5.6 \\
2.2 \\
1.4 \\
1.1 \\
1.1 \\
1.2 \\
.6 \\
100.0\end{array}$ \\
\hline \multicolumn{3}{|l|}{ Marital Status: } \\
\hline $\begin{array}{l}\text { Married } \\
\text { Non-married } \\
\text { Total }\end{array}$ & $\begin{array}{l}217 \\
141 \\
358 \\
\end{array}$ & $\begin{array}{l}60.6 \\
39.4 \\
100.0\end{array}$ \\
\hline \multicolumn{3}{|l|}{ Education: } \\
\hline $\begin{array}{l}\text { High school } \\
\text { Diploma/ Certificate } \\
\text { Degrees } \\
\text { Masters } \\
\text { Others } \\
\text { Total }\end{array}$ & $\begin{array}{l}84 \\
85 \\
128 \\
56 \\
5 \\
358 \\
\end{array}$ & $\begin{array}{l}23.5 \\
23.7 \\
35.8 \\
15.6 \\
1.4 \\
100.0 \\
\end{array}$ \\
\hline \multicolumn{3}{|l|}{ Monthly Income RM } \\
\hline $\begin{array}{l}\text { Less Than RM } 20,000 \\
\text { RM 21,000- RM 30,000 } \\
\text { RM 31,000- RM 41,000 } \\
\text { RM 41,000- RM 50,000 } \\
\text { Over RM 50,000 } \\
\text { Total }\end{array}$ & $\begin{array}{l}14 \\
50 \\
63 \\
104 \\
127 \\
358 \\
\end{array}$ & $\begin{array}{l}43.9 \\
14.0 \\
17.6 \\
29.1 \\
35.5 \\
100.0 \\
\end{array}$ \\
\hline \multicolumn{3}{|l|}{ Visit Malaysia: } \\
\hline $\begin{array}{l}\text { Yes } \\
\text { No } \\
\text { Total }\end{array}$ & $\begin{array}{l}173 \\
185 \\
404 \\
\end{array}$ & $\begin{array}{l}48.3 \\
51.7 \\
100.0 \\
\end{array}$ \\
\hline \multicolumn{3}{|c|}{ Number Years Traveling Malaysia: } \\
\hline $\begin{array}{l}\text { 0-2 Years } \\
\text { 2-4 Years } \\
\text { 4-6 Years } \\
\text { 6-8 Years } \\
\text { 10 years and above } \\
\text { Total }\end{array}$ & $\begin{array}{l}207 \\
65 \\
57 \\
26 \\
3 \\
358\end{array}$ & $\begin{array}{l}57.8 \\
18.2 \\
15.9 \\
7.3 \\
.8 \\
100.0\end{array}$ \\
\hline
\end{tabular}




\section{Factor Analysis}

Table 2 and 3 show the results of the factor analysis which was used to validate the items for the variables. The study used the principle components factor analysis with a varimax rotation while all items are required to achieve a factor loading of 0.4 and above to be included in any of the factors as suggested by Minai and Lucky (2012). Both Table 1 and Table 2 show the factor loadings, Eigenvalue and the percentage of variance explained for information source before and choice of traveling mode.

\section{CORRELATION, VALIDITY AND RELIABILITY ANALYSIS RESULTS}

For this analysis, the Pearson correlation analysis technique was employed to determine the strength the relationship between information sources and choice of traveling mode. The result in table 4 shows that information sources $\left(\mathrm{r}=.195^{* *}\right)$ have very weak association with choice of traveling mode.

These were determined using both Kasier-Meyer-Olkin (KMO) and Cronbach Alpha coefficient scores. The minimum acceptable limit for both validity and reliability is 0.5 as suggested by Lucky and Minai (2011) and Minai and Lucky (2012). The result depicted in Table 4 indicates that both variables (Information source before and choice of traveling mode) showed KMO and Cronbach

Table 2. Information sources before traveling

\begin{tabular}{|l|l|}
\hline \multicolumn{1}{|c|}{ Information sources before traveling } & \multicolumn{1}{c|}{ Factor Loading 1 } \\
\hline Q1B & .803 \\
\hline Q1C & .784 \\
\hline Q1A & .491 \\
\hline Eigenvalue & 1.66 \\
\hline Percentage of variance explained (\%) & 27.7 \\
\hline Kasier-Meyer-Olkin & .513 \\
\hline Bartlett's test of sphericity approx. chi square & 173.061 \\
\hline df. & 15 \\
\hline Sig. & .000 \\
\hline
\end{tabular}

Table 3. Choice of traveling mode

\begin{tabular}{|l|l|}
\hline \multicolumn{1}{|c|}{ Choice of traveling mode } & \multicolumn{1}{c|}{ Factor Loading 1 } \\
\hline Q12E & .759 \\
\hline Q12D & .659 \\
\hline Q12B & .611 \\
\hline Q12C & .553 \\
\hline Eigenvalue & 1.795 \\
\hline Percentage of variance explained (\%) & 30.90 \\
\hline Kasier-Meyer-Olkin & .628 \\
\hline Bartletts' test of spericity approx. chi square & 144.215 \\
\hline df. & 10 \\
\hline Sig. & .000 \\
\hline
\end{tabular}


Alpha coefficient scores above 0.5 respectively, suggesting that the items measuring the variables are both valid and reliable respectively.

\section{HYPOTHESES TESTING}

This was done using the standard regression analysis technique and Statistical Package for Social Science (SPSS) version 21 after the data have been subjected to basic assumptions of regression analysis. It was used to test the influence of information source and choice of travelling mode among Arab tourists coming to Malaysia. As depicted in Table 5 below, the result revealed that information source before traveling is statistically significant with choice of traveling mode among Arab tourists coming to Malaysia at $\mathrm{p}<0.005$.

The $\mathrm{R}$ square for the model which is a measure of the percentage of variance in the dependent variable that is explained by the variation in the independent variable is 0.025 . This implies that almost $2.5 \%$ of the variance in choice of traveling mode is explained by variance in information source before traveling. The $2.5 \% \mathrm{R}$ square suggests that there is poor influence of information source before traveling on choice of traveling mode. The sig. value is .003** indicating that there is a statistically significant relationship between information source before traveling and choice of traveling mode.

\section{DISCUSSION ON THE FINDINGS}

The major objective of this study is to investigate how the information sources before traveling affect the choice of traveling mode among the Arab tourists coming to Malaysia. In other words, how information sources before traveling influences the choice of traveling mode among the Arab tourists coming to Malaysia. It equally looked into how travel agents, tourism service providers and tourism information centers influence the choice of traveling mode of the Arab tourists coming to Malaysia.

First and foremost, the study found overall significant and positive support for the influence of information source before traveling on the choice of traveling mode among the Arab tourists coming to Malaysia. This implies that credible information sources before traveling are indispensable in making choice of traveling modes. Hence, there is a need for tourism service providers and tourism information centers sources to ensure that credible information is presented in a very persuasive way for better decision on choosing traveling modes among the Arab tourists. As reported by Fisher, Petersen and Burstein (2017) for example, there can be some ways of linking a bundle of relevant information in a logical and persuasive form, which would allow the user to follow on her/his queries

Table 4. Correlation, validity and reliability results

\begin{tabular}{|l|l|l|l|l|l|}
\hline \multicolumn{1}{|c|}{ Variables } & \multicolumn{1}{c|}{$\mathbf{1}$} & \multicolumn{1}{c|}{$\mathbf{2}$} & \multicolumn{1}{c|}{ No of Items } & \multicolumn{1}{c|}{ KMO } & Cronbach Alpha \\
\hline $\begin{array}{l}\text { Information } \\
\text { Source }\end{array}$ & 1 & & 3 & .513 & .56 \\
\hline $\begin{array}{l}\text { Choice of } \\
\text { traveling mode }\end{array}$ & $.195^{* *}$ & 1 & 3 & .628 & .54 \\
\hline
\end{tabular}

${ }^{* *}$. Correlation is significant at the 0.01 level (2-tailed).

Table 5. Test result of regression analysis summary for the independent variables

\begin{tabular}{|l|l|l|l|l|l|}
\hline \multicolumn{1}{|c|}{ Variables } & \multicolumn{1}{|c|}{$\mathbf{R}^{2}$} & \multicolumn{1}{c|}{ Adjusted $\mathbf{R}^{2}$} & \multicolumn{1}{c|}{ F } & Beta & t \\
\hline $\begin{array}{l}\text { Information } \\
\text { source before }\end{array}$ & .025 & .022 & 9.127 & .158 & 3.021 \\
\hline
\end{tabular}


further without necessarily initiating a new search. Therefore, providing information in a variety of sources such as through the travel agents, tourism service providers and tourism information centers would go a long way in helping the Arab tourists to make better decisions on which mode of traveling should choose when traveling. The implication of this finding is that the information source used by the Arab tourists before coming to Malaysia determines which traveling mode, they use in coming to Malaysia for tourism pressure. It suggests that Arab tourists coming to Malaysia must first think about their sources of information before deciding on their choice of traveling mode when coming to Malaysia. Hence, sources where the Arab tourists obtained their information before traveling is a function or determinant of choice of traveling mode. That is to say that when they obtained information from quality and reliable sources such as through the travel agents, tourism service providers and tourism information centers, then they make inform and better decisions on the mode of traveling. This finding is consistent with the previous studies by Gronflaten $(2009,2008)$ where it was affirmed that information sources significantly predict information choice strategies.

Secondly, the result on the dimensions of information source before variable revealed that both tourism service providers and tourism information centers sources but not travel agent source are significantly related to the choice of traveling mode among Arab tourists coming to Malaysia. In other words, the study found that both tourism service providers and tourism information centers sources are significant determinants of the choice of traveling mode among Arab tourists coming to Malaysia. While the study failed to establish a significant relation between travel agent source and the choice of traveling mode among Arab tourists coming to Malaysia. Thus, the hypothesis that travel agent will significantly affect the choice of traveling mode among Arab tourists coming to Malaysia is not supported. This implies that many Arab tourists coming to Malaysia prefer using tourism service providers and tourism information centers sources for their choice of traveling mode rather than travel agents' source. It suggests that both tourism service providers and tourism information centers sources offer them the relevant and important information that help them to make choose among traveling mode. Thus, the use of Air, train or water by the Arab tourists to come to Malaysia for their tourist adventure is mainly affected by tourism service providers and tourism information centers sources, and not travel agent source. The finding collaborates the previous studies by Gronflaten (2009) and Gronflaten (2008) which affirmed that information source was related to information choice strategy.

\section{CONCLUSION AND IMPLICATION}

The purpose of this article is to investigate which information sources among Arab tourists coming to Malaysia use before traveling to make choice of their traveling mode. Therefore, using a survey data from 385 Arab tourists coming to Malaysia allowed the study to answer the research question. The study concludes that information source before traveling which comprises of tourism service providers and tourism information centers sources affect the choice of traveling mode of the Arab tourists coming to Malaysia. While travel agent source offers no contribution to the choice of traveling mode of the Arab tourists coming to Malaysia.

One major implication of this study is that without quality and reliable information sources before traveling Arab tourists traveling to Malaysia would make wrong choices on the mode of traveling, and this could make them to be at risk of suffering adverse outcomes and spending significant funds without achieving their satisfaction or tourism desires.

\section{Suggestion for Future Studies}

One major limitation to this study is the data utilized in this study only reflect the Arab tourists or pleasure travelers coming to Malaysia. Other tourists from other countries or continents are not accounted for. Thus, a larger more diversified sample from different economic and cultural regions could enhance the generalization of the findings of this study. 


\section{REFERENCES}

Abzakh, A. A., Ling, K. C., \& Alkilani, K. (2013). The impact of perceived risks on the consumer resistance towards generic drugs in the Malaysia pharmaceutical industry. International Journal of Business and Management, 8(3), 42. doi:10.5539/ijbm.v8n3p42

Al-khateeb, B. A. A. (2019). Personal characteristics and situational characteristics as the mediating factors in the relationship between information source and information choice strategies of the Arab tourists in Malaysia. International Journal of Business Information Systems, 31(4), 479-498.

Al-Khateeb, B. A. A., \& Dahalin, Z. B. M. (2013). Information source, information channels and information choice: The mediating effect of personal characteristics.

Al-khateeb, B. A. A., \& Dahalin, Z. B. M. (2015). The Determinants of Information Choice Strategies: Information Source and Information Channels. Journal of Southeast Asian Research, 2015, c1-c11. doi:10.5171/2015.689506

Amadi, G., \& Gand Paul, A. K. (2017). Influence of student-teacher communication on students' academic achievement for effective teaching and learning. American Journal of Educational Research, 5(10), 1102-1107. doi:10.12691/education-5-10-12

Amin, H. U., \& Khan, A. R. (2009). Acquiring Knowledge for Evaluation of Teachers Performance in Higher Education using a Questionnaire.

Arab News. (2019, June 17). Malaysia seeks to attract more Arab tourists. www.arabnews.com/node/1511676/ travel

Cavana, R. Y., Delahaye, B. L., \& Sekaran, U. (2001). Applied business research: Qualitative and quantitative methods: John Wiley \& Sons Australia.

Chetthamrongchai, P. (2017). The influence of travel motivation, information sources and tourism crisis on tourists' destination image. J. Tourism Hospit, 6(02), 278. doi:10.4172/2167-0269.1000278

Chiappa, G.D. and Balboni, B. (2019). Travellers' choice of information sources and information channels for domestic trips. Munich Personal RePEc Archive.

Chu, C., \& Luckanavanich, S. (2018). The influence of social media use and travel motivation on the perceived destination image and travel intention to Taiwan of the Thai people. International Journal of Arts and Commerce, $7(3), 22-36$.

Fisher, J., Petersen, A., \& Burstein, F. (2017). The importance of reliable information sources for prospective medical travellers. In Proceedings of the Australasian Conference on Information Systems, Hobart, Australia. Academic Press.

Fodness, D., \& Murray, B. (1997). Tourist information search. Annals of Tourism Research, 24(3), 503-523. doi:10.1016/S0160-7383(97)00009-1

Grønflaten, Ø. (2005). Sources and Channels of Tourism Information. Gold Coast: Griffith University.

Grønflaten, Ø. (2009a). Predicting travelers' choice of information sources and information channels. Journal of Travel Research, 48(2), 230-244. doi:10.1177/0047287509332333

Grønflaten, Ø. (2009b). The tourist information matrix-differentiating between sources and channels in the assessment of travellers' information search. Scandinavian Journal of Hospitality and Tourism, 9(1), 39-64. doi:10.1080/15022250902761280

Hassan, N. (2009). The Middle East market: Business \& tourism outlook. Retrieved from http://www. businessguideseries.com/

Hitchcock, M. J., King, V. T., \& Parnwell, M. (2009). Tourism in Southeast Asia: challenges and new directions. Nias Press.

Jansen, B. J., \& Rieh, S. Y. (2010). The seventeen theoretical constructs of information searching and information retrieval. Journal of the American Society for Information Science and Technology, 61(8), 1517-1534. 
Khurshid, K. (2008). A study of the relationship between the professional qualifications of the teachers and academic performance of their students at secondary school level. Paper presented at the Proceedings of World Academy of Science, Engineering and Technology. Academic Press.

Korneliussen, T., \& Greenacre, M. (2016). Information sources used by European tourists: A cross-cultural study. Barcelona GSE.

Krejcie, R. V., \& Morgan, D. W. (1970). Determining sample size for research activities. Educational and Psychological Measurement, 30(3), 607-610. doi:10.1177/001316447003000308

Lucky, E. O.-I., \& Minai, M. S. (2011). Re-investigating the effect of individual determinant, external factor and firm characteristics on small firm performance during economic downturn. African Journal of Business Management, 5(26), 10846.

Malaysia Tourism Promotion Board (MTPB). (2019). Malaysia tourism statistics in brief. Retrieved from https:// www.tourism.gov.my/statistics

Mat, A. B. C., Zakaria, H. A. B., \& Jusoff, K. (2009). The importance of Arabic language in Malaysian tourism industry: Trends during 1999-2004. Canadian Social Science, 5(4), 12-17.

Minai, M. S., \& Lucky, E. O.-I. (2012). An empirical examination of the effect of entrepreneurs' biological makeup on the firm performance. International Business Management, 6(6), 621-628. doi:10.3923/ibm.2012.621.628

Raitz, K., \& Dakhil, M. (1989). A note about information sources for preferred recreational environments. Journal of Travel Research, 27(4), 45-49. doi:10.1177/004728758902700409

Saidu, N. (2006). Fundamental of Research. Ikeja, Lagos: Sanbio-Nes.

Salman, A., \& Hasim, M. S. (2012). Factors and competitiveness of Malaysia as a tourist destination: A study of outbound middle east tourists. Asian Social Science, 8(12), 48. doi:10.5539/ass.v8n12p48

Scudder, S. F. (1980). Communication theory as a universal law. Retrieved from https://en.mwikibooks.org

Sekaran, U. (2006). Research methods for business: A skill building approach. John Wiley \& Sons.

Tan, W. D., \& Arnott, D. R. (1999). Managerial information acquisition and the World Wide Web: A theoretical background. Paper presented at the Proceedings of the 5th International Conference, The International Society for Decision Support Systems. Academic Press.

Zikmund, W., Babin, B., Carr, J., \& dan Griffin, M. (2013). Business research methods. South Western Cengage learning. 
Bilal A. A Al-khateeb is an assistant professor in the Department of Business Administration, Faculty of Economics and Administrative Sciences, Imam Mohammad Ibn Saud Islamic University, Riyadh 11564, Saud Arabia. He received his B.A degree in Business Administration specialization (MIS) from Sindh University in 2007, his M.B.A degree in Business Administration specialization (MIS) from Sindh University in 2007, and his PhD degree in Management Information System from Universiti Utara Malaysia, Kedah, Malaysia in 2015. His research interest includes information sources and information channels, personal and situational characteristics, information choice strategies, information sharing, and Blockchain.

Asef M. A Al-khateeb is an assistant professor in the Department of Computer and information Sciences, College of Shari'a and Islamic Studies, Imam Mohammad Ibn Saud Islamic University, Al-Ahsaa 1730, Saudi Arabia. He received his B.C.I.T degree in Computer and Information Technology (CIT) from Sindh University (Pakistan) in 2002, his M.C.S degree in Computer Sciences from University of Science Malaysia (USM) in 2006, and his PhD degree in Computer Sciences from University of Science Malaysia (USM) in 2012. His research interest includes high performance (computer clusters, grid computing, cloud computing), and bioinformatics. 